\title{
A Critical Review of the Main Approaches on Financial Market Dynamics Modelling
}

\author{
Lucian Pasca ${ }^{1}$
}

DOI 10.1515/jheec-2015-0017

\begin{abstract}
While the interpretation of the EMH has changed over the last 50 years, its meaningfulness continues to define our view on how financial markets work. Competing approaches such as BFT and ACT have been proven to be in particular cases of an infinite spectrum of market states; all come under the framework of the $A M H$. The flexible framework of the $A M H$ enables a trans-disciplinary approach for the study of financial system dynamics. An evolutionary and contextual view on financial systems allows researchers to use techniques and instruments from quantum mechanics and statistical physics to quantify volatility and provide an interpretation to the cognitive processes underlying investor decision making. Such a context also enables to tackle the interpretation of information processing at a cognitive level through consideration of quantum effects in the price formation mechanism.
\end{abstract}

Keywords: efficient markets hypothesis, behavioral finance theory, algorithm complexity theory, adaptive markets hypothesis, econophysics

JEL Classification: C22, C29, G12, G15

${ }^{1}$ PhD Student, West University of Timisoara, Faculty of Economics and Business Administration, Blvd. Pestalozzi 16, Timisoara 300115, Romania, Email: luciangpasca@gmail.com 


\section{Introduction}

While classical economics rely on simple assumptions on market functioning:1) homogeneous and perfectly rational agents; 2) instantly processed information;3) efficient markets; such models cannot explain a multitude of financial phenomena. This is largely due to the existence of heterogeneous investor categories-in terms of strategy, investment horizon, risk aversion, etc.-which increases the complexity of financial systems exponentially. While each investor processes new information individually, their actions influence and are influenced by the actions of other investors. Even models incorporating investor heterogeneity and behavioral biases have applicability limited to the phenomena they have been developed for. They cannot provide a holistic overview of the financial system's functioning.

Such limitations determined the emergence of new research directions studying financial markets from an evolutionary perspective, where investors are not rational or irrational, but adapt their behavior to existing market conditions with the objective of maximizing their utility. Financial markets can be seen as complex systems with evolutionary dynamics characterized by continuous investor interaction. As opposed to other non-financial systems, the dynamics of financial markets is influenced primarily by human behavior. Models which combine elements from evolutionary biology and information processing theory with concepts from quantum mechanics enable the understanding of a financial system's dynamics through the study of its aggregated characteristics (at a macro level); without being required to analyze the interdependencies of its component parts (at a micro level).

The mathematical modelling of financial asset price dynamics is a complex issue, as price levels are determined by the offer-demand interaction and are known only after the transaction occurs. Price levels are subject to how investors receive and interpret the new information entering the market. Although attempts to model the movement of financial asset prices can be traced back to the pioneering work of Bachelier (1990) in the $19^{\text {th }}$ century, the debate on a unified theory on financial time series dynamics is far from being closed. In the following sections, the main approaches to modelling the dynamics of financial markets are presented.

\section{Efficient markets hypothesis}

Since its initial formulation by Fama $(1965,1970)$ and later formalization by Samuelson (1965), the Efficient Market Hypothesis (EMH)is probably the most well-known and debated matter in finance theory. Its simplicity (e.g., rational investors, normally distributed returns) determined the emergence of mathematical models that attempted to explain the price formation mechanism, catalyzing the vast literature that followed. Majority of models are based on the assumption that investors are perfectly rational with an unbiased behavior and able to fully and instantaneously incorporate any new information that enters the market. As a consequence, price levels are determined by all 
the information available on the market and any change is a consequence of new information entering the market. Since the arrival of new information is random in nature, any price change will also be random. Thus, price changes can be modelled as stochastic processes. Such an approach was proposed for the first time by Bachelier (1990), followed by a plethora of other authors. For a detailed presentation on the historical development of asset price stochastic models see Mantegna and Stanley (2000)and Shiryaev (1999). In such a scenario, the utility of deterministic models in to determine the dynamics of financial price series comes under question, as the dynamics of financial time series (price, volume, number of transactions) resembles a stochastic process which is characterized by the unpredictability of future outcomes.

The mathematical formalization of the EMH was done by Samuelson (1965)who, based on the assumption that markets are efficient and investors rational, used martingales to show the relation between the anticipated price value of a financial asset at time $t+1$ and past price values $E\left[q_{t+1} \mid q_{0}, q_{1}, \ldots, q_{t}\right]=q_{t}$. However, the relation holds only when the information set is restricted to the historical time series of the price; which is the case of weak form efficiency. Now if $I_{t}$ is the set of available information at time $t$, the relation can be interpreted as a martingale $E\left[q_{t+1} \mid I_{t}\right]=q_{t}$ and the price difference as a random walk $E\left[q_{t+1}-q_{t} \mid I_{t}\right]=0$.The return series follows a normal distribution of zero mean and finite variance $\left(q_{t+1}-q_{t}\right) \sim N\left(0, \sigma^{2}\right)$.The martingale is, intuitively, a fair game model where the chance to win and the chance to lose are equal. Therefore, if financial asset price changes are described by a fair game, one cannot predict the dynamics solely based on the historical series. While EMH describes the scenario of idealized markets, in reality residual inefficiencies accumulate over time, providing speculators the opportunity to make a profit by exploit these inefficiencies (if they manage to conceive winning strategies).

Since its introduction, the EMH has been under the constant scrutiny of critics, both at a theoretical (LeRoy, 1976) and empirical level (Malkiel, 2003). However, as Fama (1970) highlighted, any critics to the EMH can be simply reduced to a critic of the underlying price formation model. Therefore, the theory cannot be adequately tested, until there is a consensus on a model that describes the price formation mechanism. Nevertheless, a restrictive theoretical framework and the presence of irregularities in financial time series have led to the emergence of heavy criticism to the validity of the EMH. The main argument was that a martingale model cannot explain various anomalies such as high volatility, abnormal returns or the formation of financial bubbles. A series of empirical studies showed that the dynamics of financial price series is not always described by stochastic processes and that price changes are not always random.

There are a multitude of arguments, both theoretical and empirical derived from the statistical analysis of financial time series, which dismiss the martingale model as a good solution for describing the price formation mechanism. For high frequencies (over a week) it is largely accepted that the distributions of asset price returns are not Gaussian; although they might be for lower frequencies. Mandelbrot (1963) raised awareness about the persistence of fat tails in return series, arguing that extreme price changes (over5\%) 
happen to often to be described by a Gaussian distribution. Mandelbrot (1963) showed that price changes cannot be described by normally stable processes, but by $\alpha$-stable Levi processes or Pareto stable processes. It was again Mandelbrot (1969) who suggested that processes governing the distribution of returns can be locally Gaussian. Fama (1965) and many other authors confirmed empirically the existence of fat tails in the distribution of financial return series. Since then a multitude of models explaining the dynamics of financial returns emerged, primarily based on the assumption that the distribution of price returns follows a power law. For a detailed review of the literature on non-Gaussian models for price returns see Jondeau et al. (2007). Stable processes are often associated with fractals and fractal Brownian motion-first proposed by Mandelbrot (1967) to model the long term dependence of financial returns-therefore, called processes with memory. Mandelbrot (1967) showed that irregular financial time series are scale invariant, mimicking a fractal behavior. Those irregularities display resemblances at different scales, their statistical properties are same regardless the scale the series is studied at. Peters (1994) proposed the Fractal Markets Hypothesis as alternative to the EMH, highlighting the importance of information and investment horizon in investor behavior. He proposed liquidity as the main driving force of market equilibrium, as alternative to efficiency.

Grossman and Stiglitz (1980) considered the EMH unsustainable from an economic perspective as efficiency implies no information costs, which would eventually lead to the lack of motivation to collect financial data. They proposed instead to view efficiency in relative terms when comparing two different markets (e.g. spot vs futures). Shiller (1981) and LeRoy and Porter (1981) obtained high return volatilities which could not be explained by the change in dividends and concluded that the volatility cannot be explained by models with rational investor behavior. Lo and Mackinlay (2001) argue that over limited periods of time it is possible to consistently beat the market through a competitive advantage (e.g. higher information quality, superior technology, financial innovation). The predictive models become more flexible if such incentives for financial innovation are taken into consideration. Rubinstein (2001), Malkiel (2003) and Ball (2009) studied various financial markets anomalies (e.g. market momentum, informational asymmetry, mean reverting, seasonality, day of the week effects, volatility clustering) from a perspective which is compatible with the EMH. They propose to define rationality in a less restrictive manner, and even suggest the existence of several types of rationality; plausible assumptions if one considered that information is non-uniformly distributed across market participants.

Lo and MacKinley (2001) see the EMH as an extreme version in an infinite spectrum of possible stages. The solution might be a shift form the EMH framework to less restrictive and more flexible models which support both efficiency and a certain degree of predictability. Campbell et al. (1997) showed that in modern economic theory even in the context of perfectly rational agents there can be a certain degree of predictability in the dynamics of financial asset prices. Elements such as market structure, trading costs, investor expectations influenced by the changes in market conditions and business environment can induce a certain degree of predictability. Campbell et al. (1997) 
highlighted that a degree of predictability is required to compensate for the risk investors are willing to take.

\section{Behavioral finance theory}

The inefficiency of financial markets is mostly attributed to the biased behavior of market participants. A large set of such deviations from presumed rationality have been studies in the literature; for almost any financial anomaly there exists a model outside of the EMH framework that puts it on a specific investor bias. The emergence of such models paved the way for the emergence of the Behavioral Finance Theory (BFT). Behavioral models combine elements from human psychology with elements from neoclassical economics to study the decision making process of investors-by applying the principles of scientific research to the socio-cognitive and behavioral biases of investors-and its impact on market conditions. Cognition and preferences influence strategy development, risk aversion and resource allocation.

The two main causes of market inefficiency highlighted by Barberis and Thaler (2002)are1) the limited power of arbitrage which leads to situations where the market price does not reflect its fundamental characteristics even though there are no profit generating opportunities and 2)the biased behavior of investors which leads to apparently irrational decisions. By using a model with overlapping generations where there exist irrational noise investors (they trade based on short-term information shocks), De Long at al. (1990) explained financial anomalies such as volatility clustering, mean reverting and sub-evaluation of closed mutual funds. They put these anomalies on the existence of investors with poor financial education. Their apparently irrational behavior can determine and maintain the divergence of prices from their fundamental values. Such phenomena is not offset by arbitrageurs due to the short-term horizon and the limited risk they can take as their resources are mostly borrowed and the owners seek short term returns and limited risk. Rational investors cannot always off-set the mistakes of irrational ones.

De Bondt and Thaler (1985) studied the propensity of investors to over-react to new information and showed that financial assets which in previous periods had the highest return tend to have lower return in the next period and vice-versa. Barberis et al. (1997) concluded that investors give a higher importance to more recent price values and too little importance to the causes that determined their dynamics. Haugen (1996) argues that short-term over-reactions determined by market momentum leads to mean reverting episodes over the long-term, as the market acknowledges the disequilibrium and corrects the prices. Chan et al. (1997) showed that new information entering the market is processed and absorbed by investors slowly, leading to longer periods of under/over evaluations of prices. Such slow integration can be partially explained by the persistence of investor preferences and the lagged change in anticipations. As highlighted by Daniel et al. (1998), another important factor is the nature of information. Daniel et al. (1998) concluded that investors overreact to private information and under react to public information. Smith et al. (1988) simulated a financial market 
environment in controllable laboratory conditions and in about two-thirds of the cases obtained financial bubbles causing the market to crash. They highlighted that the divergence of the anticipated price from its underlying value persists even in the case of experienced investors. However, there is a negative relation between the gap and investor experience, suggesting a learning-by-doing process. Huberman and Regev (2001) showed that optimism and pessimism can be extremely contagious, with mimetic behavior leading to an exponential increase in price volatility over relatively short periods of time. Shanthikumar (2004) showed that small household investors are more exposed to having a distorted behavior as compared to professional investors with a strong and sound financial education. Nevertheless, Haigh and List (2005) suggest that the latter group displays a more pronounced distortion on certain behavior.

Nevertheless, the utility of such models is limited to the phenomena they were built to explain-which are very particular cases of market architecture and investor behaviorunable to provide a broader understanding of the financial systems functioning. While BFT provides models that explain specific anomalies observed in the financial markets, the main limitation of such an approach is that it cannot provide an integrated model that captures all aspects of the financial ecosystem.

\section{Algorithmic complexity theory in financial markets}

The Algorithmic Complexity Theory (ACT), introduced by the works of Kolmogorov (1965) and Chaitin (1966), postulates that a time series is considered unpredictable if the amount of information cannot be compressed in a more compact form. In other words, the most efficient algorithm that reproduces the series has the same length as the series itself. Given that one of the most important consequences of the EMH is that future price values cannot be predicted based on the historic series, one can interpret the efficiency from a complexity theory perspective. The link between market efficiency and return unpredictability is that a time series with dense non-redundant economic information (as is the case with $\mathrm{EMH}$ ) has similar characteristics as a randomly generated series. The large amount of non-redundant information in financial asset price series makes it difficult to identify a subset pertaining to an observable pattern in the series, which could be used to predict future outcomes. As a result, the challenge to predict price changes resides from the abundance of information and not from the lack of it. When new information changes the price in a non-random way the market is not fully efficient. However, it is exactly this modification that allows us to detect in the price series that new information entered the market. These inefficiencies are exploited by arbitrageurs until the market integrates all new information and becomes efficient again. Trading patterns are the result of heterogeneous investor groups of different size, know-how and information accessibility. As opposed to the framework of EMH, where information is free and instantly assimilated by the market, in reality valuable information is more expensive and investors require different amounts of time to fully disseminate the data. Thus, instead of being an instantaneous process, the information assimilation is a gradual inflow of data, reflecting only partially the market information. 
Ivkovic and Weisbenner (2005) suggested that trading performance should be seen as a consequence of the financial education and know-how of investors, and not as a consequence of any psychological or behavioral bias. Coval and Moskowitz (2001) and Malloy (2005) showed that investors trading locally obtain superior returns than those trading across different geographies. In same line, Kacperczyk et al. (2005) showed that mutual funds managing portfolios concentrated in sectors where they have expertize (an informational advantage) have superior returns than those with portfolios diversified across several sectors. Such empirical results suggest the utility of a behavioral approach based on information theory. Classical economics theory of information based on investor rationality (proposed by Grossman and Stiglitz, 1980), assumes that investors can correctly valuate the information and is therefore willing to pay a fix amount to have access to it. However, the major limit of this theory is that it does not explain how investors process the information.

A more robust framework from this perspective is provided by the entropy theory proposed by Shannon (1948), which describes the informational transmission process for communication systems. Shannon (1948) built a measure for the quantity of information that a system can receive from a source. The same process can be applied to living organisms, including investors on financial markets. Chen (2005) proposed the interpretation of information as a reduction in entropy, not only from a mathematical point of view (the case of Shannon entropy) but also from a physical point of view. The physical cost of information is tightly correlated with the economic cost. Such an approach can explain some important properties of information processing in financial markets such as the fact that more valuable information comes at a higher price. Also, the amount of data an investor can assimilate is limited by the degree of informational asymmetry and the capacity to efficiently process the information. Understanding the information requires a certain level of know-how, which is developed over long periods of time. And not last, the information value is negatively correlated with the number of investors which understand it. An investor who buys the shares of a company before the company becomes successful will obtain higher returns than someone who buys the company's shares after it is in high demand. Hong and Stein (2003) showed that investor heterogeneity is given by the level of financial knowledge and the cost they are willing to pay for information. They highlight that the heterogeneity plays an important role in the price formation process. Although the cost of financial information decreased significantly with the consumerization of trading and the emergence of financial service companies, its value also declined because of the wider public's access to the information.

Empirical studies show that price patterns in financial markets are tightly correlated with patterns in information processing, stressing out the link between information theory and behavioral finance. Chen (2003) showed that the majority of psychological patterns reflect either physical or biological constraints (e.g. need for food and shelter) or an evolutionary adaptation to more efficient information processing (e.g. learning, change in strategy). The latter approach is within the theoretical framework proposed by Lo (2004), namely that financial markets should be regarded from an evolutionary perspective where certain investor species are becoming more efficient in processing 
the information and therefore survive in the financial ecosystem while species get extinct.

\section{Adaptive markets hypothesis}

While the fundamental premises of EMH and BFT, i.e. perfect rationality versus bounded rationality, seem to make then mutually incompatible, they continue to provide insights on how financial markets work, though at different scales and time horizons. Authors such as Samuelson (1965), Malkiel (2003)or Lo and Khandani (2008) argue that over the long term any uncertainty related to market efficiency is eliminated as over longer horizons any price disequilibrium is corrected when anomalies tend to offset each other. Over the long term, markets always reach a stage where investors are rational and the information is processed efficiently. While the EMH provides a description of financial markets over the long-term at an aggregated level, the BFT provides a short-term local interpretation of market functioning.

Formalized by Lo (2004), the Adaptive Markets Hypothesis (AMH) suggests a new approach for the study of financial phenomena by applying principles of evolution such as competition, reproduction and natural selection to financial interactions. The theory replaces the concept of resource optimization from neoclassical theory with the concept of satisfaction, a sub-optimal solution. The latter is an adaptive process similar to natural selection, and it is based on successive trial and error phases until a local equilibrium is reached. Any change in market conditions might subsequently lead to a change in equilibrium conditions. Lo (2004) compared capital markets to an ecosystem of market participant species of different size and form, and where profits represent the food source. In such a framework, the market dynamics is determined by food availability, which in turn determines changes in the number and structure of existing species. Verheyden et al. (2013), by analyzing the events that lead to and those that followed the global financial crisis from 2008, identify the elements of an ecosystem, which when taken out of its natural equilibrium it triggered a chain effect leading to the extinction of certain species and the appearance of others, until a new equilibrium is reached. The change in efficiency degree over time is consistent with the evolutionary interpretation of financial market. Over the long term markets process information efficiently, up to when an external perturbation factor breaks the equilibrium. Until a new equilibrium is restored investors must adapt to the new market conditions and during that process they sometimes display an apparently irrational behavior when judged by previous market conditions. Once the equilibrium is restored, investors become rational as per the new market conditions and the information is processed efficiently.

In the framework of AMH, EMH and BFT are only two very particular states from an infinite spectrum of market possibilities. Therefore, financial markets are not efficient of inefficient in an absolute sense; instead their degree of efficiency changes over time subject to modification in the structural, functional or institutional market characteristics. Still, this theory is not complete and displays some conceptual 
inconsistencies. As noted by Verheyden et al. (2013), evolutionary theory and natural selection cannot fully explain the process of how financial markets re-become efficient once taken out of equilibrium, given that investor species with certain behavioral biases survive the shock. Although the AMH does not fully explain the functioning of financial systems is does provide a more flexible framework, allowing the use of more heterodox approaches toward modelling financial time series dynamics. As emphasized by Segal and Segal (1998), some irregularities in financial asset price changes caused by the apparent irrational behavior of investors can be explained by quantum effects. Moreover, Haven (2003) and Haven (2005) utilize principles from quantum mechanics to describe the stochastic processes from financial markets.

\section{Econophysics and quantum-like approach}

Complex systems defined as structures where component entities compete for available resources-space and energy in physics, profit and services in economy-and have an adaptive behavior to changing environment are characteristic for both physics and economics. Broadly, the field of economy can be defined as the science that studies the process through which economic agents utilize available resources efficiently to produce and distribute goods and services. Mantegna and Stanley (2000) described financial markets as complex open systems where the non-linear interaction of investors determines a change in their behavior (through feedback integration). Similar to mechanical systems, the functioning of financial markets is governed by laws stable over longer periods of time.

The complexity of financial markets, the uncertainty associated with their dynamics and the existence of large volumes of financial information drew the attention of researchers from other research areas interested in studying the statistical properties of financial time series. While still considered an emerging interdisciplinary field at the intersection of physics, mathematics and economy, Econophysics utilizes elements from probability theory, statistical analysis and chaos theory to study the nature of economic phenomena and the functioning of markets. Financial markets are continuously monitored, fueled by the generalized implementation of electronic trading, leading to the accumulation of extremely large datasets of financial information. This enabled the development and empirical validation of deterministic models for financial price dynamics. A large literature on the analogies between physical and economic systems emerged. As alternatives to representative agent models which dominated the literature on macroeconomic phenomena, econophysicists proposed approaches from statistical mechanics based on concepts from chaos theory and disordered systems theory to study financial systems. Techniques such as mean property extraction from the dynamics of a system's component parts are proven to be useful even in the case of economic systems. Models from mechanical physics enable econophysicists to study the aggregated behavior of financial systems without being required study in detail the behavior of its component parts beforehand. This can be done by using concepts such as stochastic dynamics, correlation effects, scaling theory, self-organizing systems and self-similarity, which do not require a detailed understanding of the structure and functioning of the system at a micro level.

It has also been shown that stylized facts, analogy to the principles and laws from physics, 
can be identified for financial and economic phenomena. On financial return properties, Chakraborti et al. (2011) proposed the existence of fat tails, volatility clustering, absence of autocorrelation and aggregational normality as stylized facts, which have been confirmed empirically by several studies. Other authors such as Pagan (1996), Guillaume et al. (1997) and Cont (2001)studied and proposed other stylized facts. Gopikrishnan et al. (1999) tested the return distribution of S\&P500, NIKKEI and Hang-Seng indices across different frequencies and obtained that for frequencies lower than 4 days the return distribution follows a power law of coefficient $\alpha=3$ (above the interval that characterizes stable Levy processes)suggesting the presence of fat tails. For frequencies over 4 days the distributions converged to a Gaussian. Pagan (1996) and Cont et al. (1997)obtained that the autocorrelation function rapidly converges to zero even for lags of one minute, suggesting that lack of correlation between returns. While Mandelbrot (1963)was the first to highlight the heteroscedasticity of financial time series-big price changes are followed by other big changes, while small price changes are followed by small changesSornette (2003)compared this phenomena with a phase transition triggered by mimetic behavior and perpetual competition between investors.

Notions from thermodynamics andseismology are used to explain and interpret asset price dynamics, risk diversification and bubble formation. Black and Scholes (1973) and Merton (1973) paved the way for option pricing theory, one of the most active sub-fields of financial research. They showed that in certain conditions the time evolution of a financial option's price is described by the heat diffusion equation. Sornette (2009) studied the mechanics of speculative bubble formation followed by market corrections (financial crisis) and concluded that such extreme events have a higher frequency as would be given by a power law. Moreover, the triggers that lead to the financial bubble's burst are endogenous to the system and represent an accumulation of systemic instability determined by mimetic behavior and, over-optimistic and unrealistic investor expectations. The general belief that portfolio diversification minimizes risk was partially contradicted by Battiston et al. (2009) which use dynamic models to describe individual risk formation as coupled stochastic processes. The authors concluded that if the complexity of the risk sharing network between individuals rises above a certain threshold, the positive effect of diversification is eliminated. Market instability also increases with the increasing complexity of used financial instruments. The adaptive nature of financial markets makes it possible to construct indicators for the timely detection of such events. Sornette (2003) documented the episodes of important market crashes from developed and emerging countries and found that such events are predictable. Zumbach et al. (2000), Maillet and Michel (2003) and Negrea (2014) proposed measures that assess the magnitude of market crises similar to the Richter scale from seismology. Weber et al. (2007) showed that immediately after a significant drop in market index the volatility is best described by an Omori process (used in the study of earthquakes) - a shock followed by replicas at a decay rate that is described by a power law with exponent close to 1 . Moreover, the volatilities of the aftershocks are also described by Omori processes. This indicates that the return volatility over different time horizons has memory and tends to replicate itself, phenomena explained in scaling theory.

A particular research direction within econophysics is the study of financial phenomena using concepts from quantum mechanics. In such framework financial markets are complex systems where individual investors interact in similar way particles interactin a physical system. Due to the uncertainty related to financial markets advanced theories 
and instruments from statistical physics have been used to model the dynamics of financial systems (e.g. perturbation theory, Feynman-Kac path-integral, differential manifolds, random matrix theory). Meyer (1999) and Eisert et al. (1999) proposed utilization of quantum cryptography and overlaid financial functions to develop trading strategies, which lead to the development of quantum game theory.

Under the incidence of Newton's motion law, classical mechanics is a deterministic theory in which the exact position of a particle is known precisely at any given moment in time $t$. Such framework could only be used to describe the dynamics of a financial asset price with zero volatility. However, in quantum mechanics a particle's position cannot be precisely determined. Instead, at any given moment in time one can estimate a probability space for all possible positions of the particle. This framework describes more accurately the context of financial markets, where the dynamics of asset prices is characterized by uncertainty and investors can only assign a probability to a certain event. This time, the analogy between a particle's position and a financial asset's price (with non-null volatility) is plausible. Another important analogy is that similar equations are used to describe the dynamics of physical and financial systems. Haven (2002) showed that the Black-Scholes-Merton equation for the dynamics of option prices is a particular case of the Schrodinger equation for dynamics of quantum particles. Moreover, Heisenberg's uncertainty principle from physics is also valid in a financial systems context, in the sense that price level (position) and price volatility (momentum) cannot be measured accurately at the same time.

Bohm and Hiley (1993) and Hiley and Pylkkanen (1997) have studied the informational interpretation of Bohmian mechanics (particular case of quantum mechanics) and its implications in the field of cognitive sciences. Segal and Segal (1998) argued that irregularities in financial asset price changes can be explained by quantum effects, while Haven (2003) and Haven (2005) utilize principles from quantum mechanics to describe the stochastic processes from financial markets. Other quantum game theory models for financial systems have been proposed by Piotrowski (2003) and Piotrowski and Sladkowski (2004). Goncalves and Goncalves (2007) studied multi-fractality and turbulence in financial markets by deploying a model from quantum game theory based on boson properties. Research from biology suggests that quantum mechanics might play an important role in the decision making process at a neuronal level. Khrennikov (2007) highlighted that the formalism of quantum mechanics can be applied to social sciences, with possible profound implications in the functioning of financial markets. Choustova (2007) used Bohmian mechanics as the theoretical framework to develop a model that describes a financial system's dynamics, including through a quantum potential component that captures the influence of investor's interaction and behavioral changes. A mathematical formalization for the volatility components of a financial systems' dynamics has been proposed by Dima et al. (2015); also with an interpretation of the price formation process based on heterogeneous investor groups.

Principles from quantum physics can be applied if financial markets are considered complex systems where investors interact with each other similar to the way particles interact in a quantum environment. The main advantage of a quantum-like approach, as opposite to a behavioral model where the psychological and cognitive profiles of investors need to be taken into consideration, is that all the microlevel characteristics of the system are reflected at a macro level through the dynamics of the system itself. 


\section{Concluding remarks}

The study of financial phenomena enables investors to understand the underlying mechanics of market functioning and develop the required know-how to manage liquidity and risk. Furthermore, robust models allow policy makers and regulatory institutions to adopt informed decisions that ensure the stability and proper functioning of the financial environment.

In the context of accelerated globalization and increasing trans-frontier dependences, all coupled with high trading speeds, financial systems are continuously monitored and therefore generate a large and diversified amount of financial data (financial asset prices, trading volumes, offer/demand orders all at frequencies down to few milliseconds). This has drawn the attention of an increasing number of researchers trying to model the dynamics of such systems. The rising interest resides in the particularities of financial systems which place the study of financial phenomena at the intersection between social sciences (phycology, sociology, politics) and fixed sciences (mathematics, physics, engineering, biology). Thus researchers with long tradition in the study of financial phenomena have been joined by a large number of physicians and engineers which employ theories and techniques from their domain of expertise to explain economic processes. Accessibility of such data to an increasing audience catalyzed on one hand the research on financial price formation mechanism and on the other hand the empirical confirmation of financial time series stylized facts.

While the EMH and BFT have been proven to be particular states from an infinite spectrum of market possibilities, the AMH seems to provide a flexible enough framework that enables a trans-disciplinary approach for the study of financial system dynamics. The evolutionary and contextual approach from AMH allows researchers to use techniques and instruments from quantum mechanics and statistical physics to quantify market volatility and provide an interpretation to the cognitive processes underlying the decision making of investors. A quantum-like framework even allows to capture the influence of soft market determinants (e.g. change in investor behavior and expectations) on the aggregated dynamics of financial system.

\section{References}

Bachelier, L., 1900, Theorie de la speculation, Annales Scientifiques de 1'Ecole Normale Superiere, $\quad 3^{\text {rd }} \quad$ Series, $\quad$ Vol. $17, \quad$ pg. $21-86, \quad$ available athttp://archive.numdam.org/ARCHIVE/ASENS/ASENS 1900317 /ASENS 19003

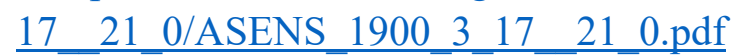

Ball, R., 2009, The Global Financial Crisis and the Efficient Market Hypothesis: What Have We Learned?, Journal of Applied Corporate Finance, Vol. 21 No. 4, pg. 8-16, available athttp://papers.ssrn.com/sol3/papers.cfm?abstract id=1502815

Barberis, N., Shleifer, A., Vishny, R., 1997, A Model of Investor Sentiment, NBER, Working Paper No. 5926, available athttp://faculty.som.yale.edu/nicholasbarberis/bsv jnl.pdf 
Barberis, N., Thaler, R., 2002, A Survey of Behavioral Finance, NBER, Working Paper No. 9222, available athttp://faculty.som.yale.edu/nicholasbarberis/ch18_6.pdf

Battiston, S., Gatti, D.D., Gallegati, M., Greenwald, B.C., Stiglitz, J.E., 2009, Liaisons Dangereuses: Increasing Connectivity, Risk Sharing, And Systemic Risk, NBER, Working Paper No. 15611, available athttp://www.nber.org/papers/w15611.pdf

Black, F., Scholes, M., 1973,The pricing of options and corporate liabilities, Journal of Political Economy $81 \quad$ (3), pg. 637665, available athttp://efinance.org.cn/cn/FEshuo/The\%20Pricing\%20of\%20Options $\% 20$ and $\% 20$ Corpor ate\%20Liabilities.pdf

Bohm, D., Hiley, B., 1993, The Undivided Universe: An Ontological Interpretation of Quantum Theory, Routledge, First Edition, available athttp://www.researchgate.net/publication/224043431_The Undivided_Universe_An_On tological_Interpretation_of_Quantum_Mechanics

Campbell, J. Y., Lo, A. W., MacKinlay, A. C., 1997, The Econometrics of Financial Markets, Princeton University Press, available athttps://is.muni.cz/el/1456/podzim2011/MPM AEM1/10730658/10732669/9294156/el 1456 jaro2009/NotSortedYet/Campbell_Lo_MacKinlay_1997 The Econometrics_of Financial_Markets.pdf

Chaitin, G. J., 1966, On the Length of Programs for Computing Finite Binary Sequences, J. Assoc. Comp. Math., Vol. 13, pg. 547-569, available athttps://www.cs.auckland.ac.nz/ chaitin/acm66.pdf

Chakrabortia, A., Tokea, I.M., Patriarcab, M., Abergela, F., 2011, Econophysics : Empirical facts and agent-based models, available athttp://xxx.tau.ac.il/pdf/0909.1974.pdf

Chan, K., Gup, B., Pan, M.S., 1997, International Stock Market Efficiency and Integration: A Study of Eighteen Nations, Journal of Business Finance \& Accounting, Vol. 24, No. 6, pg. 803-813, available athttp://onlinelibrary.wiley.com/doi/10.1111/14685957.00134/abstract

Chen, J., 2003, An Entropy Theory of Psychology and its Implication to Behavioral Finance, Financiele Studievereniging Rotterdam Forum, Vol. 6, pg. 26- 31, available athttp://web.unbc.ca/ chenj/papers/psychology.pdf

Chen J., 2005, Information Theory and Market Behavior, ICFAI Journal of Behavioral Finance, 2(4), 25-45, available athttp://web.unbc.ca/ chenj/papers/info.pdf

Choustova, O., 2007, Toward quantum-like modeling of financial processes, arXiv:quantph/0109122v5, available athttp://arxiv.org/pdf/quant-ph/0109122.pdf

Cont, R., 2001, Empirical properties of asset returns: stylized facts and statistical issues, Quantitative Finance, Vol. 1 (2), pg. 223-236, available athttp://wwwstat.wharton.upenn.edu/ steele/Resources/FTSResources/StylizedFacts/Cont2001.pdf

Cont, R., Potters, M., Bouchaud, J.P., 1997, Scale Invariance and Beyond, SSRN eLibrary, available athttp://www.springer.com/physics/complexity/book/978-3-540-64000-4

Coval, J., Moskowitz, T., 2001, The geography of investment: Informed trading and asset prices, Journal of Political Economy, Vol. 54, pg. 1-39, available athttp://www.people.hbs.edu/jcoval/Papers/Geography.pdf

Daniel, K., Hirshleifer, D., Subrahmanyam, A., 1998, Investor Psychology and Security Market under- and Overreactions, The Journal of Finance, Vol. 53, No. 6, pg. 1839-1885, available athttp://deepblue.lib.umich.edu/handle/2027.42/73431 
De Bondt, W., Thaler, R., 1985, Does the Stock Market Overreact?, Journal of Finance, Vol. 40, No. 3, pg. 793-805, available athttp://home.business.utah.edu/finml1/fin787/papers/debondtthaler1985.pdf

De Long, B., Shleifer, A., Summers, L., Waldmann, R., 1990, Noise Trader Risk inFinancial Markets, The Journal of Political Economy, Vol. 98, No. 4, pg. 703-738, available athttp://ms.mcmaster.ca/ grasselli/DeLongShleiferSummersWaldmann90.pdf

Dima, B., Pasca, L., Preda, C., 2015, A financial wave model for stock indices, Journal of Economic Computation and Economic Cibernetics Studies and Research, Issue 4/2015, available at http://www.ecocyb.ase.ro/nr20154/01\%20\%20Dima \%20Bogdan,\%20Lucian\%20PASCA.pdf

Eisert, J., Wilkens, M., Lewenstein, M., 1999, Quantum games and quantum strategies, Phys. Rev. Lett. 83, pg. 3077-3080, available athttp://arxiv.org/pdf/quant-ph/9806088v3.pdf

Fama, E., 1965, The behavior of stock market prices, Journal of Business, Vol. 38, pg. 34105 ,

available athttp://stevereads.com/papers to read/the behavior_of_stock_market prices.pdf

Fama, E.F., 1970, Efficient Capital Markets: A Review of Theory and Empirical Work, Journal of Finance, Vol. 25,pg. 383, available athttp://efinance.org.cn/cn/fm/Efficient $\% 20$ Capital $\% 20$ Markets $\% 20 \mathrm{~A} \% 20$ Review $\% 20$ of \%20Theory\%20and\%20Empirical\%20Work.pdf

Ghirardi, G.C., Rimini, A., Weber, T., 1986, Unified dynamics for microscopic and macroscopic systems, Physical Review D, Vol. 34, Issue. 2, available athttp://journals.aps.org/prd/abstract/10.1103/PhysRevD.34.470

Goncalves, C.P., Goncalves, C., 2007, An Evolutionary Quantum Game Model of Financial Market Dynamics - Theory and Evidence, Working Paper, Social Science Research Network, available athttp://papers.ssrn.com/sol3/papers.cfm?abstract id=982086

Gopikrishnan, P., Plerou, V., Amaral, L.N., Meyer, M., Stanley, H.E., 1999, Scaling of the distribution of fluctuations of financial market indices, Physical Review E, 60, pg. 53055316, available athttp://arxiv.org/pdf/cond-mat/9905305.pdf

Grossman, S.J., Stiglitz, J.E., 1980, On the Impossibility of Informaționally Efficient Markets, The American Economic Review, pg. 393-408, available athttps://www.aeaweb.org/aer/top20/70.3.393-408.pdf

Guillaume, D., Dacorogna, M., Dave, R., Muller, U., Olsen, R., Pictet, O., 1997, From the bird's eye to the microscope: A survey of new stylized facts of the intra-daily foreign exchange markets, Finance and Stochastics 1 (2), pg. 95-129, available athttp://ww.longmemory.com/returns/Guillaume-etal1997.pdf

Haigh, M., List, J., 2005, Do professional traders exhibit myopic loss aversion? An experimental analysis, Journal of Finance, Forthcoming, available athttp://karlan.yale.edu/fieldexperiments/papers/00052.pdf

Haven, E., 2002,A discussion on embedding the Black-Scholes option pricing model ina quantum physics setting, Physica A 304 (2002) 507-524, available athttp://www.sciencedirect.com/science/article/pii/S0378437101005684

Haven, E., 2003, An 'h-Brownian motion' of stochastic option prices, Physica A, Vol. 344, pg. 151-155

Haven, E., 2005, Pilot-wave theory and financial option pricing, International Journal of TheoreticalPhysics 


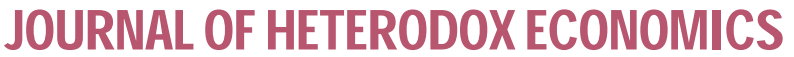

athttp://link.springer.com/article/10.1007\%2Fs10773-005-8973-3\#page-1

Haugen, A., 1996, The New Finance: The Case Against Efficient Markets, Pearson, available athttp://www.jstor.org/discover/10.2307/2329361 ?uid=3738920\&uid=2\&uid=4\&sid=211 04551934331

Hiley, B., Pylkkanen, P., 1997, Active information and cognitive science-A reply to Kieseppa, Pylkkanen, P., Pylkko, P., A. Hautamaki (Eds.), Brain, Mind and Physics, IOS Press, Amsterdam, pg. 123, available athttp://books.google.ro/books?id=IdEpIXyXew4C\&pg=PA64\&redir esc=y

Huberman, G., Regev, T., 2001, Contagious Speculation and a Cure for Cancer: A Nonevent that Made Stock Prices Soar, The Journal of Finance, Vol. 56, No. 1, available athttp://onlinelibrary.wiley.com/doi/10.1111/0022-1082.00330/abstract

Ivkovic, Z., Weisbenner, S., 2005, Local does as local is: Information content of the geography of individual investors' common stock investments, Journal of Finance, Vol. 60, pg. 267-306, available athttp://www.business.illinois.edu/weisbenn/RESEARCH/PAPERS/JF_Locality_Feb200 5 267-306.pdf

Jondeau, E., Poon, S.H., Rockinger, M., 2007, Financial Modeling Under Non-Gaussian Distributions, Springer Verlag, Springer Finance, available athttp://www.gbv.de/dms/ilmenau/toc/508397626.PDF

Kacperczyk, M., Sialm, C., Zheng, L., 2005, On the industry concentration of actively managed equity mutual funds, Journal of Finance, Vol. 60, pg. 1983-2011, available athttp://pages.stern.nyu.edu/ sternfin/mkacperc/public_html/conc.pdf

Khrennikov, A., 2007, Quantum-like Probabilistic Models outside Physics, arXiv:physics/0702250, available athttp://arxiv.org/pdf/physics/0702250.pdf

Kolmogorov, A. N., 1965, Three Approaches to the Quantitative Definition of Information, Problems of Information Transmission Vol. 1, No. 4, available athttp://www.tandfonline.com/doi/abs/10.1080/00207166808803030?journalCode=gcom 20\#.VGfIavmsVFo

LeRoy, S., 1976, Efficient capital markets: Comment, Journal of Finance, Vol. 31, pg. 139141, available athttp://www.e-m-h.org/LeRo76.pdf

LeRoy, S., Porter, D., 1981, The present-Value Relation: Tests Based on Implied Variance Bounds, Econometrica, Vol. 49, No. 3, pg. 555-574, available athttp://www.jstor.org/discover/10.2307/1911512?uid=3738920\&uid=2\&uid=4\&sid=211 $\underline{04551934331}$

Lo, A.W., Khandani, A.E., 2008, What Happened To The Quants inAugust 2007?, NBER, Working Paper No. 14465, available athttp://web.mit.edu/alo/www/Papers/august07.pdf

Lo, A.W., MacKinlay, C., 2001, A Non-Random Walk Down Wall Street, Princeton University Press, available athttps://is.muni.cz/el/1456/jaro2009/PMAPEM/NotSortedYet/A_NonRandom_Walk_down_Wall_Street_Lo_MacKinlay_pdf

Lo, A.W., 2004, The Adaptive Markets Hypothesis: Market Efficiency from an Evolutionary Perspective, Journal of Portfolio Management, a 30-a Lansare Aniversare, pg. 15-29, available athttp://opim.wharton.upenn.edu/ sok/papers/1/JPM2004.pdf

Maillet, B., Michel, T., 2003, An index of market shocks based on multiscale analysis, Quant. Finance Vol.

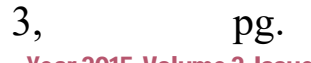
88-97, available 
athttp://www.tandfonline.com/doi/abs/10.1088/1469-

7688/3/2/303? journalCode=rquf20\#.VGffCfmsVFo

Malkiel, B., 2003, The Efficient Market Hypothesis and Its Critics, Journal of Economic Perspectives, Vol. 17, No. 1, pg. 59-82, available athttp://eml.berkeley.edu/ craine/EconH195/Fall_14/webpage/Malkiel_Efficient\%20Mkt $\underline{\text { s.pdf }}$

Malloy, C., 2005, The geography of equity analysis, Journal of Finance, Vol. 60, pg. 719-755, available athttp://onlinelibrary.wiley.com/doi/10.1111/j.1540-6261.2005.00744.x/abstract

Mandelbrot, B., 1969, Long-Run Linearity, Locally Gaussian Process, H-Spectra And Infinite Variances, International Economic Review, Vol. 10, No. 1, pg. 82-111,

Mandelbrot,B., 1963, New methods instatistical economics, Journal of Political Economy, 71:421-440, available athttp://users.math.yale.edu/ bbm3/web pdfs/032statisticalEconomics.pdf

Mandelbrot, B., 1967, The variation of some other speculative prices, The Journal of Business, Vol. 40. No. 4, pg. 393-413, available athttp://web.williams.edu/Mathematics/sjmiller/public_html/341Fa09/econ/Mandelbroit VariationCertainSpeculativePrices.pdf

Mantegna, R.N., Stanley, H.E., 2000, An Introduction to Econophysics: Correlations and Complexity inFinance, Cambridge University Press, available athttp://polymer.bu.edu/hes/book-mantegna00stanley.pdf

Merton, R., 1973, Theory of rational option pricing, The Bell Journal of Economics and Management Science, pg. 141-183, available athttp://www.people.hbs.edu/rmerton/Theory $\% 20$ of $\% 20$ Rational $\% 200$ ption $\% 20$ Pricing.p $\underline{\mathrm{df}}$

Meyer, D.A., 1999, Quantum strategies, Phys. Rev. Lett. 82, pg. 1052-1055, available athttp://arxiv.org/pdf/quant-ph/9804010v1.pdf

Negrea, B., 2014, A statistical measure of financial crises magnitude, Physica A 397, pg. 5475, available athttp://www.sciencedirect.com/science/article/pii/S0378437113010972

Pagan, A., 1996, The econometrics of financial markets, Journal of Empirical Finance, No. 3 (1), pg. 15-102, available athttp://press.princeton.edu/titles/5904.html

Peters, E., 1994, Fractal Market Analysis: Applying Chaos Theory to Investment and Economics, Wiley, New York, available athttp://eu.wiley.com/WileyCDA/WileyTitle/productCd-0471585246.html

Piotrowski, E.W., 2003, Fixed point theorem for simple quantum strategies inquantum market games, Physica A, Vol. 324, pg. 196-200, available athttp://arxiv.org/pdf/quantph/0210183.pdf

Piotrowski, E.W., Sladkowski, J., 2004, Quantum games infinance, arXiv:quant$\mathrm{ph} / 0406129 \mathrm{v} 1$, available athttp://arxiv.org/pdf/quant-ph/0406129.pdf

Rubinstein, M., 2001, Rational Markets: Yes or No? The Affirmative Case, Financial Analysts Journal, Vol. 57, No. 3,pg. 15-29, available athttp://www.haas.berkeley.edu/groups/finance/WP/rpf294.pdf

Samuelson, P. A., 1965, Proof That Properly Anticipated Prices Fluctuate Randomly, Industrial Management Review, 6:2, pg. 41, Spring, available athttp://stevereads.com/papers_to_read/proof that properly_anticipated prices_fluctuate randomly.pdf 
Segal, W., Segal, I.E., 1998, The black-Scholes pricing formula inthe quantum context, Proceeding of National Academy of Sciences of the USA, Vol. 95, pg. 4072-4075, available athttp://venus.usc.edu/PAPERS/RKHS/Segal3.pdf

Shannon, C., 1948, A mathematical theory of communication, The Bell System Technical Journal, Vol. 27, pg. 379-423, pg. 623-656, available athttp://cm.belllabs.com/cm/ms/what/shannonday/shannon1948.pdf

Shanthikumar, D., 2004, Small Trader Reactions to Consecutive Earnings Surprises, working paper, available athttp://papers.ssrn.com/sol3/papers.cfm?abstract id=449882

Shiller, R., 1981, Do Stock Prices Move Too Much to be Justified by Subsequent Changes in Dividends?, The American Economic Review, pp. 421-436, June, available athttps://www.aeaweb.org/aer/top20/71.3.421-436.pdf

Shiryaev, A. N., 1999, Essentials of Stochastic Finance: Facts, Models, Theory, World Scientific Publishing Company, Singapore, available atftp://150.146.129.243/incoming/ifa.rm.cnr.it/Francesco.Cairo/Public/econo/Binder1.pdf

Smith, V., Suchanek, G., Williams, A., 1988, Bubbles, Crashes, and Endogenous Expectations inExperimental Spot Asset Markets, Econometrica, Vol. 56, No. 5, pg. 11191151, September,available athttp://teaching.ust.hk/ bee/papers/040918/1988-Smith_etalbubbles.pdf

Sornette, D., 2009, Dragon-Kings, Black Swans and the Prediction of Crises, International Journal of Terraspace Science and Engineering, Vol. 2, Issue 1, December,available athttp://arxiv.org/ftp/arxiv/papers/0907/0907.4290.pdf

Sornette, D., 2003, Why Stock Markets Crash. Critical Events inComplex Financial Systems, Princeton University Press, available athttp://press.princeton.edu/titles/7341.html

Verheyden, T., De Moor, L., Van den Bossche, P. 2013, A Tale of Market Efficiency, Hub Research Papers, April,available athttp://www.capitant.be/assets/files/thesis/thesis12.pdf

Weber, P., Wang, F., Vodenska-Chitkushev, I., Havlin, S., Stanley, H.E., 2007, Relation between volatility correlations infinancial markets and Omori processes occurring on all scales, Physical Review E, 76, 016109, available athttp://journals.aps.org/pre/abstract/10.1103/PhysRevE.76.016109

Zumbach, G., Dacorogna, M., Olsen, J., Olsen, R., 2000, Measuring shocks infinancial markets, Int. J. Theor. Appl. Finance 3, pg. 347-355, available athttp://www.researchgate.net/publication/263868774_MEASURING_SHOCK_IN_FIN ANCIAL MARKETS 